\title{
Preliminary study to predict moisture content of jackfruit skin using shortwave near infrared spectroscopy
}

\author{
${ }^{1}$ Abdullah, N., ${ }^{1,3, * N a w i, ~ N . M ., ~}{ }^{2}$ Ding, P., ${ }^{1}$ Kassim. M.S.M. and ${ }^{1}$ Lazim, S.S.R.M. \\ ${ }^{1}$ Department of Biological and Agricultural Engineering, Faculty of Engineering, Universiti Putra \\ Malaysia, 43400, UPM Serdang, Selangor, Malaysia \\ ${ }^{2}$ Department of Crop Science, Faculty of Agriculture, Universiti Putra Malaysia, 43400 Serdang, Selangor, \\ Malaysia \\ ${ }^{3}$ Institute of Plantation Studies, Universiti Putra Malaysia, 43400 Serdang, Selangor, Malaysia
}

Article history:

Received: 6 July 2018

Received in revised form: 15 October 2018

Accepted: 23 October 2018

Available Online: 6

November 2018

Keywords:

Jackfruit,

Moisture Content,

Skin Scanning,

Spectroscopy,

Non-Destructive

DOI:

https://doi.org/10.26656/fr.2017.3(2).135

\begin{abstract}
Moisture content of a jackfruit is one of the main attributes used by farmers to determine the maturity level of the fruit. The objective of this preliminary research was to explore the potential application of low-cost shortwave near infrared (VSWNIR) spectroscopy to nondestructively predict moisture content of jackfruit from their outer skin. A total of 870 skin portions collected from twenty-nine jackfruit samples were used in this study. After the spectral measurement, the skin portions were dried in the oven in order to measure their moisture content (\%, wet basis, w.b.). Partial least square (PLS) method was used to develop both calibration and prediction models for calibrating the spectral data with the moisture content. This study found that the value of coefficient of determination $\left(\mathrm{R}^{2}\right)$ and root means square error of calibration (RMSEC) were 0.65 and 2.17, respectively. For the prediction model, the value of $\mathrm{R}^{2}$ and root mean square error of prediction (RMSEP) were 0.64 and 2.81, respectively. These results indicated the VSWNIR spectrometer is a promising technology for non-destructively predicting moisture content of jackfruits.
\end{abstract}

\section{Introduction}

Jackfruit (Artocarpus heterophyllus) is a nonseasonal fruit which is widely planted in tropical countries such as Brazil, Thailand, Indonesia, India, Philippines and Malaysia (Madruga et al., 2014). In Malaysia, approximately 5,097 ha of land were planted with jackfruit, producing about $28,042 \mathrm{Mt}$ of fruit with the production values up to RM58 million (DOA, 2017). Jackfruit is a high yielding crop which bears fruit all year round with its production peak is usually between June and December (Ong et al., 2006). Daud et al. (2017) stated that the average mass of a fruit ranged from 3.5 to $10 \mathrm{~kg}$ and sometimes a fruit may reach up to $25 \mathrm{~kg}$. The fruit is basically round-cylindrical in shape with the dimensions of length and diameter were about 30-100 $\mathrm{cm}$ and 25-50 cm, respectively (Leong et al., 2016).

A jackfruit maturity level can be determined by measuring several parameters of chemical composition factors such as crude fibre, colour, $\mathrm{pH}$, soluble solids sugars, organic acids, moisture content and flavour changes during ripening of jackfruit (Ong et al., 2006). The maturity determination is important because only the ripened fruit has good eating quality in terms of aroma, texture, sweetness, and taste and therefore is able to produce high quality of juice (Sim et al., 2003). However, physicochemical property of jackfruit may vary depending on different origin regions and species sources (Zhang et al., 2016). Thus, monitoring and controlling fruit maturity has become a priority issue in the jackfruit industry especially when the ripeness is perceived by customers as an important quality indicator (Sim et al., 2003).

The application of spectroscopic technology for nondestructively measuring internal quality such as sugar and moisture content of fruit which could lead to maturity detection has gained tremendous interest among researchers. Several studies reported the application of near-infrared spectroscopy (NIRS) to determine the internal quality of fruit such as watermelon (Tian et al., 2007) and apple (Qing et al., 2007). In terms of moisture content, NIRS was successfully used to predict moisture content from sugar beet (Pan et al., 2015), potato (Amjad et al., 2018) and cassava (Lertworasirikul and Tipsuwan, 2008). The measurement of moisture content using NIRS is possible due to the strong absorbance of near-infrared light by water molecules. 
Recently, rapid development of a portable visible and shortwave near-infrared spectrometer (Vis/ SWNIRS) with a wavelength range from 350 to $1100 \mathrm{~nm}$ appears promising to be employed for fruit maturity detection (Nawi et al., 2013). Unfortunately, there are no reported studies have attempted to apply Vis/SWNIRS for the prediction of moisture content from jackfruit samples. Therefore, the goal of this research was to investigate the feasibility of using Vis/SWNIRS to predict moisture content from a jackfruit. The specific objective was to develop partial least square (PLS) models for predicting moisture content from the jackfruit skin samples.

\section{Materials and methods}

\subsection{Sample preparation}

A total of twenty-nine matured Jackfruit samples were purchased from a private orchard located in Rawang, Selangor. Each jackfruit sample was first weighed to obtain the mass of the fruit. Each sample was divided into five vertical portions (top, upper middle, middle, lower middle and bottom) and six horizontal portions, giving thirty portions for each fruit samples (Figure 1). In total, 870 portions were extracted from 29 jackfruit samples. Each portion was scanned on its skin surface before it was sliced into small cube and placed into an oven dryer for moisture content measurement.
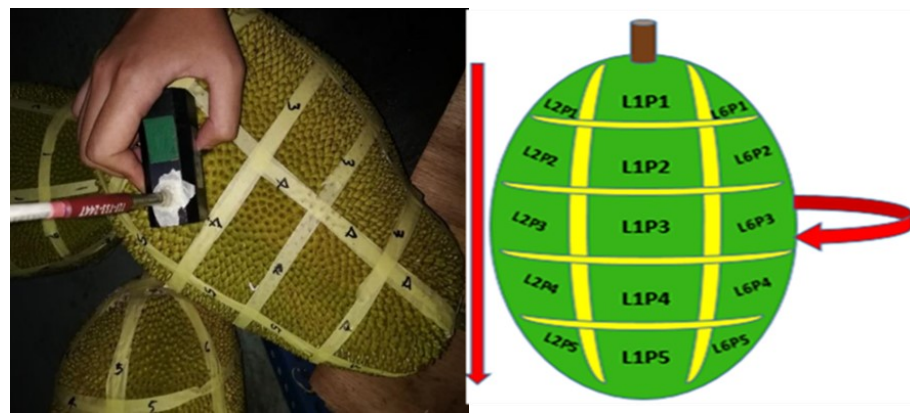

Figure 1. Marking for each portion of jackfruit skin

\subsection{Spectral acquisition}

Spectral data of the skin from each portion was recorded using visible shortwave near infrared (VSWNIR) spectrometer (Ocean Optic HR4000, Ocean Optics Inc., Dunedin, Florida) with a wavelength ranges from 200 to $1100 \mathrm{~nm}$. This high-resolution miniature fiber optic spectrometer is equipped with a chargecoupled device (CCD) detector, having an optical resolution of $0.50 \mathrm{~nm}$. The spectral data of each portion was recorded three times and averaged before it was used in the development of calibration and prediction models. A scanning distance between the spectrometer and the skin surface was fixed at $1.5 \mathrm{~cm}$. The spectral measurement was performed inside a black box which was illuminated by a halogen light source (Model: HL
2000, Ocean Optics Inc., Dunedin, Florida). The spectral data were collected and transformed into a computer with the application of SpectraSuite software (Ocean Optics Inc. Finland). In order to avoid a low signal-tonoise ratio, some obvious noise removed from both ends of the wavelength, considering only the wavelength regions between $500 \mathrm{~nm}$ and $950 \mathrm{~nm}$ were used for the calculations.

\subsection{Moisture content measurement}

After the spectral acquisition, each portion was cut into $2 \mathrm{~cm}^{3}$ cube size. The thickness of skin samples for each portion was also measured. Then, the cube portions were put in containers and placed into a conventional oven dryer with a drying temperature of $105 \pm 2^{\circ} \mathrm{C}$ for 24 hours. Conventional dryer is the most economical hot air -drying technique commonly used to dry fruits and vegetables (Omolola et al., 2017). Moisture content (MC) was determined using an air oven method according to the standard of Association of Official Analytical Chemists (AOAC International) (Pearson, 1976). The moisture content of samples was quantified indirectly, according to the loss of mass after drying at $105 \pm 2^{\circ} \mathrm{C}$. The mass of skin samples and metal container of each portion was determined based on a wet-weight basis method (MC, \%, w.b.) using the Equation (1)

$$
\text { Moisture content }(\%)=\frac{\mathrm{W}_{2}-\mathrm{W}_{3}}{\mathrm{~W}_{2}-\mathrm{W}_{1}} \times 100 \text { Where } \mathrm{W} 1
$$

is the weight of the container with the sample; W2 is the weight of the container with sample before drying; and W3 is the weight of the container with sample after drying.

\subsection{Spectral data pre-treatment}

Before calibration, the spectral data were pre-treated for optimal performance. The effect of several pretreatment methods on the performance of PLS models including smoothing by moving average, multiplicative scatter correction (MSC), first and second derivatives, standard normal variate (SNV) transformation and Savitzky-Golay were investigated. In this study, a combination of Savitzky-Golay and SNV was found to yield the best performance for PLS models. These selected pre-treatment methods were implemented using the Unscrambler X 10.3 (CAMO AS, Trondheim, Norway).

\subsection{Development of calibration and validation models}

Before PLS models were developed, principal component analysis (PCA) was applied to extract useful information from the spectra, decrease the noise and determine the optimum number of latent variables $(\mathrm{Wu}$ 
et al., 2008). PCA is a well-known chemometrics method used to search for directions of maximum variability in sample grouping and using them as new axes called principle components (PCs) or latent variables (LVs) that can be used as new variables, instead of the original data, in the following calculations (Nawi et al., 2013). PCA was also used to detect spectral outliers that might affect model performance in each data set. PCA identified outliers from the influence plot which displays the sample residual $x$-variances against leverages. Samples with high residual variance are likely to be outliers. These identified outliers were removed before modeling by PLS regression. In this study, $5 \%$ of the data were removed for being outliers.

In this study, the development of the PLS model was achieved by full cross-validation (leave-one-out) method (Nawi et al., 2013). External validation was used in this study to check the performance of the PLS models. The samples in the external validation set had not been used for the calibration development. Before calibration, samples were divided into two sets; $75 \%$ of the samples were used to develop calibration and $25 \%$ of the samples were used to validate the predictive equation (validation set).

Both PCA and PLS modelling were run using the Unscrambler X 10.3. In the end, the performance of the PLS models was evaluated by the root mean square error of calibration (RMSEC) and the coefficient of determination for calibration $\left(R^{2}\right)$ for the calibration model. For the prediction model, the root mean square error of prediction (RMSEP) and the coefficient of determination for prediction $\left(R^{2}\right)$ were used.

\section{Results and discussion}

\subsection{Statistical parameter of the samples}

The statistics characteristic of moisture content for jackfruit portions are presented in Table 1. From the table, it can be seen that the lowest and the highest values of moisture content recorded were 5.47 and $49.38 \%$ (w.b.), respectively. The average value of moisture content for all jackfruit samples was $16.74 \%$ (w. b). The variation in moisture content may indicate that the samples were harvested at different maturity levels. The average value of measured thickness of the skin was $2 \mathrm{~cm}$.

Table 1. Statistical characteristic of moisture content for skin sample from jackfruit portions

\begin{tabular}{ccccc}
\hline Parameter & $\mathrm{N}$ & Min. & Max. & Mean \\
\hline Moisture content (\%, w. b.) & 870 & 5.47 & 49.38 & 16.74 \\
\hline
\end{tabular}

3.2 Typical spectral curves for skin samples

The effective wavelength for spectral data collected from the skin surface was from $500 \mathrm{~nm}$ to $950 \mathrm{~nm}$. Typical spectral curves representing different lateral portions (top, upper middle, middle, lower middle, bottom) of jackfruit samples are shown in Figure 2. From the figure, it can be observed that the absorption peaks occurred around $550 \mathrm{~nm}, 680 \mathrm{~nm}$ and $940 \mathrm{~nm}$. The absorptions can be related to the presence of carotenoids (around $500 \mathrm{~nm})$, anthocyanins (550-600 nm), chlorophyll $(678 \mathrm{~nm})$ and water at $940 \mathrm{~nm}$ (Van et al., 2017). Thus, it can be concluded that the peak around $940 \mathrm{~nm}$ was due to the reaction of chemical characteristic and water in the skin portion.

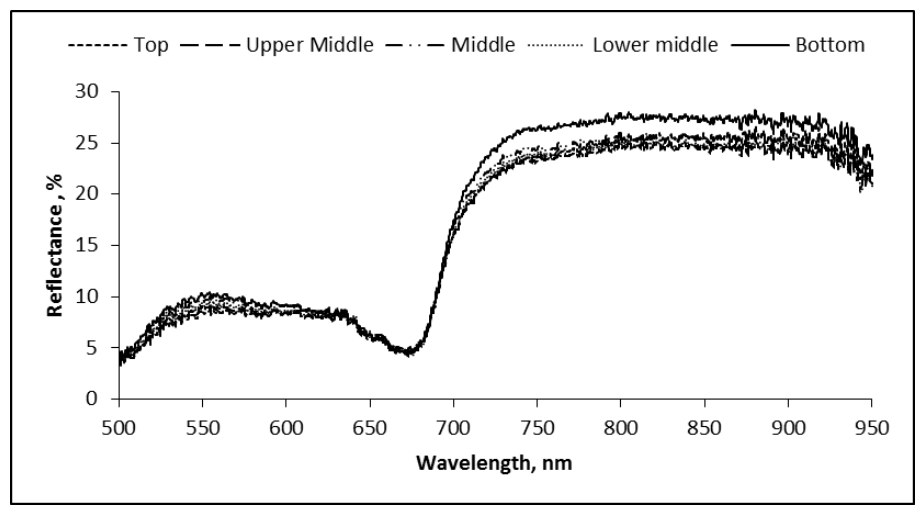

Figure 2. Reflectance spectral data for the top to bottom skin portion from $500-950 \mathrm{~nm}$

For crop industry, the outer surface texture is an important characteristic to determine their maturity level. Fan et al. (2015) stated that some changes in the spectral curve represent hidden information of different components such as water, sucrose, fructose and glucose of fruit. Thus, the reflectance spectra of moisture content detected non-destructively from skin surface may be very useful to monitor crop maturity in a field.

\subsection{Partial Lease Square model for moisture content and the spectral data}

PLS method was used to build both calibration and prediction models to calibrate the spectral data in the range of 500-950 nm with the moisture content of jackfruit skin (Figure 3). Ten latent variables (LVs) were used in both models. The figures show that for the calibration model, the values of $\mathrm{R}^{2}$ and RMSEC were 0.65 and 2.17, respectively. For the prediction model, the values of $R^{2}$ and RMSEP were 0.64 and 2.81, respectively. These findings indicated that the VSWNIR spectrometer is a promising technology to be used for monitoring the maturity of jackfruit. This preliminary study was unable to obtain higher $\mathrm{R}^{2}$ values for both models probably because of the nature of the skin surface which was homogenous in terms of surface roughness and colour (Nawi et al., 2014). 

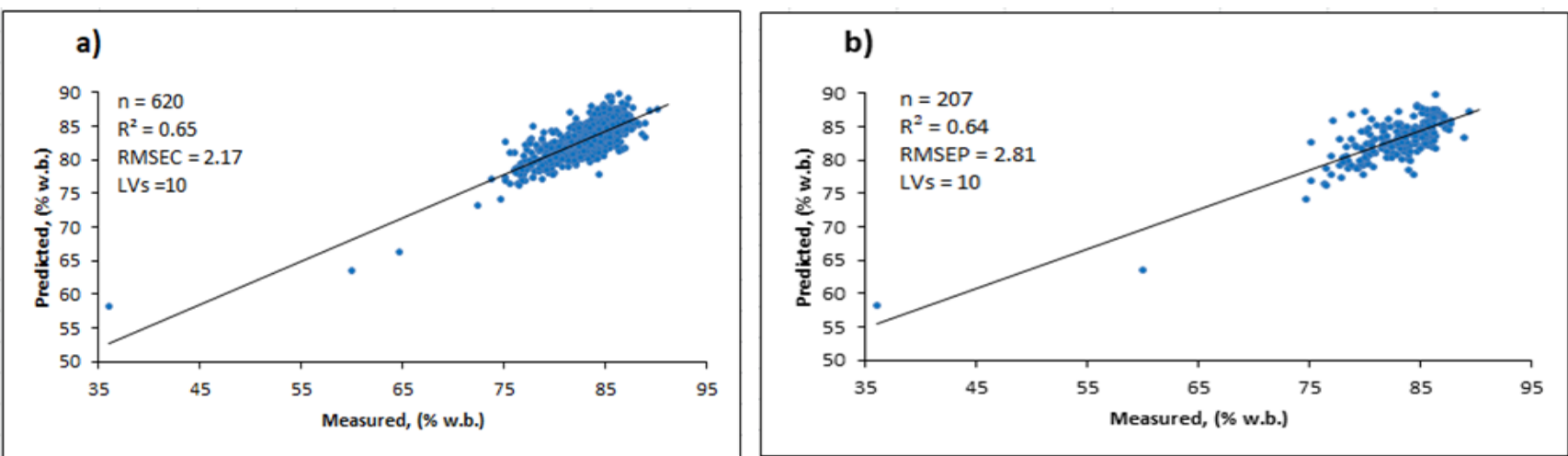

Figure 3. Scatter plots of measured vs predicted moisture content; (a) calibration model (b) prediction model

\section{Conclusion}

In conclusion, the VSWNIR spectroscopic technique has the potential to be used to predict moisture content from jackfruit skin. Owing to the nature of jackfruit skin which is rough and thorny, this preliminary study is considered successful and has gained an acceptable accuracy for predicting the moisture content of jackfruit with $\mathrm{R}^{2}$ values for both calibration and prediction models were 0.65 and 0.64 , respectively. The accuracy of the prediction could be increased if more jackfruit samples were used. Thus, it can be concluded that the VSWNIR spectrometer could be utilized for predicting maturity of jackfruit by scanning the moisture content from the skin surface.

\section{Acknowledgments}

The authors acknowledge financial support from Universiti Putra Malaysia through Putra Grant-Graduate Research Initiative Scheme (Vot no.: 9511900). The authors also acknowledge Meadow Spring Orchard Sdn. Bhd. for supplying jackfruits samples for this research.

\section{References}

Amjad, W., Crichton, S.O., Munir, A., Hensel, O. and Sturm, B. (2018). Hyperspectral imaging for the determination of potato slice moisture content and chromaticity during the convective hot air-drying process. Biosystems Engineering, 166, 170-183. https://doi.org/10.1016/j.biosystemseng.2017.12.001

Daud, M.N.H., Fatanah, D.N., Abdullah, N. and Ahmad, R. (2017). Evaluation of antioxidant potential of Artocarpus heterophyllus L. J33 variety fruit waste from different extraction methods and identification of phenolic constituents by LCMS. Food Chemistry, 232, 621-632. j.foodchem.2017.04.018

DOA. (2017). Fruit crops statistic Malaysia. Malaysia: Ministry of Agriculture and Agro-Based Industry Malaysia.

Fan, S., Huang, W., Guo, Z., Zhang, B. and Zhao, C. (2015). Prediction of soluble solids content and firmness of pears using hyperspectral reflectance imaging. Food Analytical Methods, 8(8), 1936-1946. https://doi.org/10.1007/s12161-014-0079-1

Leong, C.M., Noranizan, M.A., Kharidah, M. and Choo, W.S. (2016). Physicochemical properties of pectin extracted from jackfruit and chempedak fruit rinds using various acids. International Food Research Journal, 23(3),163-198.

Lertworasirikul, S. and Tipsuwan, Y. (2008). Moisture content and water activity prediction of semifinished cassava crackers from drying process with artificial neural network. Journal of food Engineering, 84(1), 65-74. https://doi.org/10.1016/ j.jfoodeng.2007.04.019

Madruga, M.S., de Albuquerque, F.S.M., Silva, I.R.A., do Amaral, D.S., Magnani, M. and Neto, V.Q. (2014). Chemical, morphological and functional properties of Brazilian jackfruit (Artocarpus heterophyllus L.) seeds starch. Food Chemistry, 143, 440-445. https://doi.org/10.1016/ j.foodchem.2013.08.003

Nawi, N.N., Guangnan, C. and Troy, J. (2013). Visible and shortwave near infrared spectroscopy for predicting sugar content of sugarcane based on a cross-sectional scanning method. Journal of Near Infrared Spectroscopy, 21(4), 289-297. https:// doi.org/10.1255/jnirs.1060

Nawi, N.N., Rowshon, K.M., Guangnan, C. and Troy, J. (2014). Prediction of sugarcane, L.H. quality parameters using visible-shortwave near infrared spectroradiometer. Agriculture and Agricultural Science Procedia, 2, 136-143. https:// doi.org/10.1016/j.aaspro.2014.11.020

Omolola, A.O., Jideani, A.I. and Kapila, P.F. (2017). Quality properties of fruits as affected by drying operation. Critical Reviews in Food Science and Nutrition, 57(1), 95-108. https:// doi.org/10.1080/10408398.2013.859563

Ong, B.T., Nazimah, S.A.H., Osman, A., Quek, S.Y., Voon, Y.Y., Mat Hashim, D., Chew, P.M. and Kong, Y.W. (2006). Chemical and flavour changes in 
jackfruit (Artocarpus heterophyllus Lam.) cultivar J3

during ripening. Postharvest Biology and Technology, 40(3), 279-286. https://doi.org/10.1016/ j.postharvbio.2006.01.015

Pan, L., Lu, R., Zhu, Q., McGrath, J.M. and Tu, K. (2015)., Measurement of moisture, soluble solids, sucrose content and mechanical properties in sugar beet using portable visible and near-infrared spectroscopy. Postharvest Biology and Technology, 102, 42-50. https://doi.org/10.1016/ j.postharvbio.2015.02.005

Pearson, D. (1976). The chemical analysis of foods. $7^{\text {th }}$ ed, p. 421-442. Amsterdam: Longman Group Ltd. Press.

Qing, Z., Ji, B. and Zude, M. (2007). Predicting soluble solid content and firmness in apple fruit by means of laser light backscattering image analysis. Journal of Food Engineering, 82(1), 58-67. https:// doi.org/10.1016/j.jfoodeng.2007.01.016

Sim, M.Y.M., Ahmad, M.N., Shakaff, A.Y.M., Ju, C.P. and Chen, C.C. (2003). A disposable sensor for assessing Artocarpus heterophyllus L. (jackfruit) maturity. Sensors, 3(12), 555-564. https:// doi.org/10.3390/s31200555

Tian, H.Q., Ying, Y.B., Lu, H.S., Fu, X.P. and Yu, H.Y. (2007). Measurement of soluble solids content in watermelon by Vis/NIR diffuse transmittance technique. Journal of Zhejiang University SCIENCE $B, \quad 8(2), \quad 105-110 . \quad$ https://doi.org/10.1631/ jzus.2007.B0105

Van B.R., Aernouts, B., Watté, R., Schenk, A., Nicolaï, B. and Saeys, W. (2017). Effect of maturation on the bulk optical properties of apple skin and cortex in the 500-1850 nm wavelength range. Journal of Food Engineering, 214, 79-89. https://doi.org/10.1016/ j.jfoodeng.2017.06.013

Wu, D., Feng, L., Zhang, C. and He, Y. (2008). Early detection of Botrytis cinerea on eggplant leaves based on visible and near-infrared spectroscopy. Transactions of the ASABE, 51(3), 1133-1139. https://doi.org/10.13031/2013.24504

Zhang, Y., Zhu, K., He, S., Tan, L. and Kong, X. (2016). Characterizations of high purity starches isolated from five different jackfruit cultivars. Food Hydrocolloids, 52, 785-794. https://doi.org/10.1016/ j.foodhyd.2015.07.037 